\title{
SCHAAB, Rupert, Mönch in Sankt Gallen. Zur inneren Geschichte eines frühmittelalterlichen Klosters
}

\section{Philippe Depreux}

\section{OpenEdition}

\section{Journals}

Édition électronique

URL : http://journals.openedition.org/ifha/1000

DOI : $10.4000 /$ ifha. 1000

ISSN : 2198-8943

\section{Éditeur}

IFRA - Institut franco-allemand (sciences historiques et sociales)

\section{Référence électronique}

Philippe Depreux, «SCHAAB, Rupert, Mönch in Sankt Gallen. Zur inneren Geschichte eines frühmittelalterlichen Klosters », Revue de l'IFHA [En ligne], Date de recension, mis en ligne le 01 janvier 2004, consulté le 22 septembre 2020. URL : http://journals.openedition.org/ifha/1000 ; DOI : https:// doi.org/10.4000/ifha. 1000

Ce document a été généré automatiquement le 22 septembre 2020.

(C)IFHA 


\title{
SCHAAB, Rupert, Mönch in Sankt Gallen. Zur inneren Geschichte eines frühmittelalterlichen Klosters
}

\author{
Philippe Depreux
}

1 Cet ouvrage s'inscrit délibérément en contraste avec la forme narrative par laquelle l'histoire de l'abbaye de Saint-Gall est entretenue, depuis le Casus sancti Galli dont la première rédaction date des temps carolingiens. Il s'agit ici d'une succession d'observations et de commentaires sur les listes de moines dans les divers documents liturgiques ou para-liturgiques (livre des profès, nécrologe, livre de fraternité) et leurs occurrences dans les actes de la pratique, dont on connait la richesse exceptionnelle pour le haut Moyen Âge. Il s'ensuit, non pas une synthèse comparable à la publication monumentale sur Die Klostergemeinschaft von Fulda im früheren Mittelalter, dirigée par Karl Schmid (1978), mais d'une tentative d'identification des moines dont le nom figure dans la liste des profès et d'un ensemble de notices faisant le point sur diverses questions relatives au fonctionnement de la communauté, comme - par exemple - sa structure et les titulaires des divers offices, le nombre et l'origine de ses membres, leur âge lorsqu'ils s'y agrégèrent, ou encore le fonctionnement de l'école et du scriptorium. Il s'ensuit une masse de données brutes qu'il conviendrait d'intégrer dans une histoire plus générale et qui fait de ce livre, grâce à son index, avant tout un instrument de travail pour le chercheur.

Philippe DEPREUX (MHFA) 